\title{
Lapurdum
}

Euskal ikerketen aldizkaria | Revue d'études basques |

Revista de estudios vascos | Basque studies review

$13 \mid 2009$

Numéro XIII

\section{Euskararen kasu-sistema ergatiboa ala ergatiboak? Ergatibotasunaren azterketa dialektologiko baterako lehen urratsak}

\section{Pablo Albizu}

\section{Q OpenEdition}

Journals

Édition électronique

URL : http://journals.openedition.org/lapurdum/1932

DOI : 10.4000/lapurdum. 1932

ISSN : 1965-0655

Éditeur

IKER

Édition imprimée

Date de publication : 1 février 2009

Pagination : 7-29

ISBN : $978-2-86781-409-X$

ISSN : $1273-3830$

Référence électronique

Pablo Albizu, «Euskararen kasu-sistema ergatiboa ala ergatiboak ? Ergatibotasunaren azterketa dialektologiko baterako lehen urratsak », Lapurdum [Linean], 13 | 2009, Sarean emana----an 15 avril 2013, kontsultatu 19 avril 2019. URL : http://journals.openedition.org/lapurdum/1932 ; DOI : 10.4000/ lapurdum.1932 


\section{Euskararen kasu-sistema ergatiboa ala ergatiboak? Ergatibotasunaren azterketa dialektologiko baterako lehen urratsak ${ }^{1}$}

Pablo ALBIZU

UPV/EHU

\section{Laburpena}

Txosten honetan, abiatu berri dudan ikerketa-egitasmo baten lehen emaitzak plazaratu nahi ditut. Egitasmoak euskararen kasu-sistema ergatiboa osorik, sistematikotasunez eta hizkeraz hizkera aztertu nahi du. Helburua da euskal hizkeren ergatibotasunaren sendotasuna neurtzea, ergatibotasunean eragiten duten faktoreak hizkeraz hizkera identifikatzea eta, horrenbestez, hizkeren sistema ergatiboen izaera bera zehaztea. Eta banakako sistemak ez ezik bariazioa bera ere azaldu nahi du: zer aldatzen den, non aldatzen den eta aldaketak nola mailakatzen diren. Azken batean, ikerketaproiektuak gramatikari teorikoen eta dialektologoen lan-ildoak uztartu nahi ditu.

Egitasmoaren lehen fasean datu-bilketa prestatzeari ekin nahi izan diot eta, xede horrekin, ergatibotasunaz dakigun guztia baliatuta, galdegai-zerrenda bat prestatu dut, analisi baliodun eta oso batek jaso behar lukeen informazioa zehazten duena.

\section{Abstract}

In this paper I present the first results of a new research project on ergativity in Basque that seeks to offer a thorough, systematic and cross-dialectal analysis of the Basque ergative case-system. It aims to measure the robustness of ergativity across Basque varieties, to define the factors that influence on it in each and all of the varieties of the language and, hence, to define the precise nature of all those ergative systems. And in addition to studying individual systems, it also wants to focus on the variation itself: what the changes are, where they occur and how they are graduated across varieties. This way, this research-project will eventually work toward bringing dialectologists' and theroretical syntacticians' endeavors closer.

As a first step toward this end, I have arranged a long list of variables that intends to cover all the relevant aspects of the ergativity of Basque; by doing so, I have tried to lay the grounds for further stages, in particular, for the elaboration of elicitation-tests and for the collection of data.

1. Eusko Jaurlaritzak (FFI2008-00240/FILO) eta Ministerio de Ciencia e Innovación-ek (GIC07/144-IT-21007) emandako dirulaguntzei esker egin ahal izan dut ikerketa-lan hau 
Gako-hitzak: Dialektologia, sintaxia, ergatibotasuna, modalak, datiboa, antipasiboa, trinkoak, urruneko komunztadura

Keywords: Dialectology, syntax, ergativity, modals, dative, antipassive, synthetic verbs, longdistance agreement

\section{Sarrera}

Tradizio handia dauka ergatibotasunaren gaiak gure artean, bai euskal dialektologian bai euskal gramatikagintza tipologikoan zein teorikoan. Ez da harritzekoa. Dialektologiak² hizkeren ezaugarri bereizle ugari aurkitu ditu ergatibotasunaren oinarrian dauden fenomenoetan adibidez, antipasiboak, aditz ez-ergatiboen erregimena, modalena; tipologook eta ikertzaile teorikook ${ }^{3}$ hizkuntzaren bereizgarri nagusia aurkitu dugu hor.

Edonola ere, alorrek gutxitan egin dute topo bidean, ibilbideak paraleloak izanik, meharrak izan dira-eta haien arteko zubiak: tipologook eta ikertzaile teorikook ergatibotasunaren azterketan datu dialektalak sarri erabili baditugu ere, informazio mugatua, ez-osoa aurkitu ohi dugu dialektologialanetan; dialektologoek, berriz, datu ezagunak edo interes dialektal urriko informazioa gureetan, gehienbat euskara batukoa. Eta hori diferentzia metodologikoak ez aipatzearren.

Alabaina, iruditzen zait une ona dela orain inertzia hori hautsita elkarlanari ekiteko, izan ere alorren ikerketa ildoak inoiz baino gertuago daude elkarrengadik. Hurbilketa euskal gramatikagintzan izandako bilakaerari zor zaio neurri handi batean. Batetik, datu berrien premiak bultzatuta, dezente areagotu da lan teorikoetan aldaera diatopikoak eta diastratikoak baliatzeko joera eta, horrekin batera, inportantzia hartu dute dialektologiak oraindik sakon aztertu ez dituen aldaera batzuek. Bestetik, parametroaren nozioak bariazioaren kontzeptua bera aberastu du, bariazioa ageriko txandaketetatik harago dauden ezaugarri sintaktiko abstraktuagoetara zabaldu baitu. Ikuspuntualdaketaren adibide ona dugu ergatibotasuna, ergatibo/absolutibo txandakatzeak erakusten dituzten banakako fenomenoak ez ezik kasu-sistema bera ere aldagai bihurtu dugulako: bat bera al dira euskal hizkeretako kasu-sistema ergatiboak? ergatiboak al dira euskararen kasu-sistema guztiak?

Txosten honetan, halako galderei erantzutea helburu duen ikerketa-egitasmo bat aurkeztu nahi dizuet. Proiektua oso gaztea da, ia hasiberria, nahiz eta aurreko lanetan errotzen den. Egitasmoak euskararen kasu-sistema ergatiboa hizkeraz hizkera aztertu nahi du, osorik eta sistematikotasunez. Zehatz identifikatu nahi du, lehenik, euskal hizkeren ergatibotasunaren sendotasuna, bigarrenik, haietan alternantziak eragiten dituzten faktoreak eta, hirugarrenik, sistema ergatiboen izaera bera. Eta aurreko guztien haritik, hizkeren banakako sistemak ez ezik bariazioa ere azaldu nahi du, zer aldatzen den, non aldatzen den eta aldaketak nola mailakatzen diren zehaztuta.

Egitasmoa aurrera eramateak zorroztasun metodologikoa eta datu-bilketa eskerga eskatuko du, eta horien aurretik, fenomenoaren alderdi guztien deskribapen gramatikal zehatza eta galdegai izango diren egituren hautaketa arretatsua. Deskribapenari dagokionez, konfiantza osoa daukat, euskal gramatikagintza deskribatzaileak eta batez ere teorikoak azken hiru hamarkadetan egindako ekarpenei esker, egun daukagun ezagutza maila nahikoa dela proiektuaren bideragarritasuna eta

2. Ikusi, adibidez, Aurrekoetxea eta Bidegainek (1993) eta Aurrekoetxeak (1996) osatutako ezaugarri-zerrendak.

3. Honakoak nabarmenduko nituzke: Levin (1983), Ortiz de Urbina (1987 1989), Oyharçabal (1992), Laka (1993 1995 2006), Fernández (1997), Holmer (1999), Aldai (2006), Albizu (2007) eta Rezac (2007abc). 
arrakasta bermatzeko. ${ }^{4}$ Konfiantza horren kariaz, hurrengo faseari ekin diot, hau da, datu-bilketa prestatze aldera zehatza eta osoa izan nahi duen galdegai-zerrenda bat atondu dut. Lan horren emaitza da jarraian aurkeztuko dizuedana.

\section{Galdegaiak zehazten: ergatibotasuna baldintzatzen duten faktoreak}

Hainbat dira perpaus baten ergatibotasunean eragin dezaketen faktoreak. Guztira, zazpi sailetan antola genitzake guztiak: (i) aditza, (ii) antipasibotasuna, (iii) bihurkaritasun-elkarkaritasun ez-kanonikoa, (iv) predikatu konplexuak, (v) aditz jokatuaren morfologia (trinkoa vs. perifrastikoa), (vi) aditz ez-akusatiboekiko NOR-(NORI-)NORK komunztadura bitxiak, (vii) urruneko komunztadura. Lehen bi faktoreak lexikoak-edo ditugu, trinkoen eta perifrastikoen arteko asimetriari dagokiona morfologikoa, eta gainontzekoak sintaktikoak.

\subsection{Aditzaren edo predikatuaren semantika}

Levinen (1983)ko lanaz geroztik, zenbait gramatikarik defendatu dute aditzaren edo predikatuaren esanahiak baldintzatzen duela euskaraz ERG/ABS kasuen arteko alternantzia (batez ere, Laka 2006, Holmer 1999 eta Aldai 2006). ${ }^{5}$ Banaketan garrantzitsuak diren balio semantikoak zehazterakoan egileak ez dira bat etorri: Levinek, Holmerek eta Lakak agentibotasuna nabarmendu dute; ${ }^{6}$ Aldaik, ordea, agentibotasunaren aurkako arrazoiak emanda, aditzaren pazientibotasuna hartzen du ardatz. Aldairen ustez, pazientibotasuna hiru balio semantikorekin lotzen da: (i) egoera- edo posizio-aldaketa adieraztea, (ii) telikoa izatea eta (iii) hunkiberatasuna adieraztea.

Etxepare (2003), Alberdi (2003ab) eta Aldai (2006) lanetan oinarrituta, aipatutako lau irizpideak, alegia, agentibotasuna gehi Aldairen hirurak kontuan hartzen dituen aditz zerrenda bat prestatu dut — gure galdekizuneko 110000-117000 bitarteko galdegaiak. Emaitzek banaketa semantikoaren benetako izaera (eta konsistentzia maila) zehazten lagunduko digute:

Aurrekoei portaera berezia duten hainbat aditz edo predikatu gaineratu behar zaizkie. Lehenengo eta behin, atentzioa eman [118100], merezi izan [118200] eta balio izan [118300] dauzkagu.

4. Albizu (2007) eta Rezac (2007abc) lanek biltzen eta laburbiltzen dituzte ondoen fenomeno horiek.

5. Hala ere, nagusi da gure artean ergatiboa egiturazko kasua delako ustea (ikusi, besteak beste, Ortiz de Urbina 1989, Fernández 1997, Laka 1993, 1995). Oraindik orain Albizu (2007) eta Rezac (2007ab) lanek ebidentzia sendoa eman dute hurbilketa semantikoaren aurka.

6. Betiere oso modu lausoan definituta, zeren bitartekoak ez ezik kanpo- zein barne-kausazko egiletasunak ere (alegia, kurritu, bazkaldu vs. funtzionatu, zurrungatu) batu behar dituzte. 
100000 Aditza

110000 Aspektualak

110010 telikoak

110011 hasi

110012 bukatu

110013 lotu

110020 ez-telikoak

110021 jarraitu

110022 segitu

120000 Kontrol-aditzak

120010 telikoak

120011 ausartu

120020 ez-telikoak

120021 saiatu

120021 ahalegindu

130000 Egoera-aldaketa

130010 telikoak

130011 hautsi

130012 ireki

130013 jaio

130020 ez-telikoak

130021 ilundu

130022 gogortu

130023 lotsatu

140000 Posizio-aldaketa

140010 telikoak

140011 altxatu

140012 eseri

140013 erori

140014 biratu

150000 Norazkoa duen mugimendu telikoa 150010 telikoak

150011 joan

150012 irten

150013 iritsi

150020 ez-telikoak

150021 igo

150022 jaitsi

160000 Gertaera

160010 telikoak

160011 gertatu

160012 pasatu

160013 suertatu

170000 Azaltzea

170010 telikoak

170011 azaldu

170012 desagertu

180000 Meteorologikoak

180010 telikoak

180011 berotu

180012 ilundu

180013 atertu
190000 Existentzia

190010 telikoak

190020 ez-telikoak

190021 bizi

190022 egon

190023 existitu

1110000 Konfigurazio espaziala

111010 telikoak

111011 eseri

111012 etzan

111020 ez-telikoak

111003 kabitu

1120000 Mugitzeko modua

112010 telikoak

112020 ez-telikoak

112021 dantzatu

112022 saltatu

112023 paseatu

112024 biratu

112025 paseatu

112026 errodatu

112027 nabigatu

112028 eskiatu

1130000 Giza jardunak

113010 telikoak

113020 ez-telikoak

113021 jostatu (jolastu)

113022 borrokatu

113023 jokatu

113024 entrenatu

1140000 Bizigabeen jardunak

114010 telikoak

114020 ez-telikoak

114021 funtzionatu

114022 kotizatu

114023 zirkulatu

1150000 Mintzoa

115010 telikoak

115020 ez-telikoak

115021 mintzatu

115022 solastatu

1160000 Jatorduak

116010 telikoak

116020 ez-telikoak

116021 bazkaldu

116022 afaldu

1170000 Igorpena

117010 telikoak

117020 ez-telikoak

117021 xuxurlatu

117022 oihukatu

117023 txistukatu 
*Edun aditz laguntzailea hautatu arren, predikatuok aldakortasuna erakusten dute subjektuen kasu-markatzean. ${ }^{8}$ Hona hemen adibide pare bat:

(1) Zertarako balio izan du berriro eskatzea(\%k)?

(2) Merezi du aldaerak nola hedatu diren aztertzea(\%k)

Bariazioa -TZEA perpaus konpletiboetan bakarrik agertzen zaigu, eta ez dirudi gaur egun DetS-en kasu-marka ergatiboa kolokan dagoenik., ${ }^{9} 10$ Hala ere, zuhur jokatuta eta konsistentzia hori aintzat hartu gabe, galdegai-sortan sartu ditut DetS kategoriako subjektuak. Izan ere, ez nuke erabat baztertuko euskaldun gazteen(en) artean zalantzak hauetara ere zabaltzea, batez ere subjektua aditzaren ondoren datorrenean. ${ }^{11}$

\section{Aditz bereziak}

\section{0 atentzioa eman}

118110 SUBJ atentzioa eman

118111 SUBJDetS atentzioa eman

118112 SUBJ-TZE PERPAUSA atentzioa eman

118120 atzentzioa eman SUBJ

118121 atzentzioa eman SUBJDetS

118122 atentzioa eman SUBJ-TZE PERPAUSA

\section{0 merezi izan}

118210 SUBJ merezi izan

118211 SUBJDetS merezi izan

118212 SUBJ-TZE PERPAUSA merezi izan

118220 merezi izan SUBJ

118221 merezi izan SUBJDetS

118222 merezi izan SUBJ-TZE PERPAUSA

118300 balio izan

118310 SUBJ balio izan

118311 SUBJDetS balio izan

8. Era honetako datuen aipamena ugaritzen joan da azken urteotako gramatika lanetan (Albizu 2007, Albizu eta Fernández 2006, Etxepare 2003, Euskaltzaindia 1995, Zabala 2004). Bitxikeria izan ala ez, oso handia da haien garrantzi teorikoa, zeren argudio sendoa ematen digute ERGa egiturazko kasua delako hipotesiaren alde (ik. Albizu 2007 honen inguruan).

9. Ondo aztertzeke dago aldaerak diatopikoak, diastratikoak edo idiolektalak diren. Ereduzko Prosa Gaur corpusean arakatzen hasita, berehala ohartzen gara zenbait egilek aukera biak darabiltzatela: adibidez, merezi du -tzea(k) Pello Zabalaren Naturaren mintzoa liburuan.

10. Horrek interes teoriko handiko asimetria sortzen du sisteman -TZEA perpaus konpletiboen eta DetS-en artean.

11. Aditzarekiko hurrenkerak subjektuan izan dezakeen eraginaz, ikus 2.4 atala. 


\section{SUBJ-TZE PERPAUSA balio izan \\ 118320 balio izan SUBJ \\ 118321 balio izan SUBJDetS \\ 118322 balio izan SUBJ-TZE PERPAUSA}

Antzekoak dira, ez berdinak, berdin/axola/inporta izan [118400-118500] eta iruditu [118600] aditzak. ${ }^{12}$ Aurrekoek ez bezala, oraingoek jokamolde absolutiboa zein ergatiboa onartzen dute, nahiz eta alternantziarako baldintzak zertxobait aldatzen diren: hautazko-edo ditugu lehenengoak (3), gramatikalki (aspektua, DAT komunztadura, e.a.) baldintzatua azkena (4):

(3) Berdin zait hori / Berdin dit horrek

(4) Zure proposamena egokia iruditu zait / Zure proposamenak zuzena dirudi

Jokamolde ergatiboan -TZEA subjektu konpletiboek sarri ez dute erakusten behar luketen $-k$ deklinabide-marka (5)-(6):

(5) Berdin dit arrazoia izatea(\%k)

(6) Zaila dirudi Athletik finala galtzea(\%k)

Jakina, horrek perpausen eta DetS-en arteko asimetria eta hitz-hurrenkeraren garrantzia kontuan hartzera eraman gaitu.

Bukatzeko, ez dut ahaztu nahi izan Rezac efektua (2007ab) deituko dudan fenomenoa. Ikertzaile honek hainbat adibide aurkitu ditu non subjektu ergatiboak eskatzen dituen iruditu igoera-aditzak pluraleko komunztadura egiten duen ustezko ABSko argumentu batekin. Hemen bere adibideetako bat:

(7) Kanpotik begiratuta denak desberdinak direla dirudite

(Tolosaldeko hitza, "Mundua zeharkatuz, etxetik", Esti Ezeiza 10/10/2007)

Hizkera askotan gertatzen den mugatu pluraleko kasu-marka ABSen eta ERGen arteko sinkretismoa dela medio, (7)-ko adibideak bi azterbide onar litzake. Lehenengoan, (7)-koa euskara batuko Kanpotik begiratuta denEK desberdinak direla dirudite esaldiaren parekoa litzateke, hau da, dirudite adizki jokatuak perpaus nagusira igo eta ERG kasuz markatutako denek subjektuarekin egingo luke komunztadura. Bigarrenean, berriz, urruneko numero-komunztadura gisa (ik. 2.7 atala) aztertuko genuke, hau da, euskara batuan ezgramatikala den *Badirudite kanpotik begiratuta denAK desberdinak direla esaldiarekin parekatuta; oraingoan, dirudite aditzak izenordain betegarri bat hartuko luke subjektutzat baina komunztadura menpeko perpaus konpletiboan legokeen denak argumentuarekin egingo luke distantzian. Auzi teoriko hori argitze aldera gehitu ditut [118615-

12. Albizu (2004), Albizu eta Fernández (2002, 2006), Artiagoitia (2000, 200lab), Zabala (2004). 
118619] galdegaiak: hauen artean azkena da garrantzitsuena, hitz-hurrenkeraren bitartez bereizten dituelako perpaus nagusiaren eta mendekoaren arteko mugak; gainerako laurak kontrolerako baino ez dira.

118400 berdin izan

118410 SUBJ berdin izan

118411 SUBJDetS berdin izan

118412 SUBJ-TZE PERPAUSA berdin izan

118420 berdin/axola izan SUBJ

118421 berdin izan SUBJDetS

118422 berdin izan SUBJ-TZE PERPAUSA

118500 inporta/axola izan

118510 SUBJ inporta/axola izan

118511 SUBJDetS inporta/axola izan

118512 SUBJ-TZE PERPAUSA inporta/axola izan

118520 inporta/axola izan SUBJ

118521 inporta/axola izan SUBJDetS

118522 inporta/axola izan SUBJ-TZE PERPAUSA

118600 iruditu (iduri, eman)

118610 nor(k)

118611 SUBJDetS egoki iruditu

118612 SUBJ-TZE PERPAUSA egoki iruditu

118613 egoki iruditu SUBJDetS

118614 egoki iruditu SUBJ-TZE PERPAUSA

118615 iruditu [ ERG iragk.] -ELA KONPLETIBOA

118616 iruditu [ERG irgg.] -ELA KONPLETIBOA

118617 ERG iruditu [__ iragk.] -ELA KONPLETIBOA

118618 ERG iruditu [__ iragg.] -ELA KONPLETIBOA

118619 irudituPLURALA [ERGPLURALA irgg.] -ELA KONPLETIBOA

\section{0 nor(k)-nori}

118621 SUBJDetS egoki iruditu

118622 SUBJ-TZE PERPAUSA egoki iruditu

\subsection{Antipasiboak}

Gutxi badira ere, euskarak baditu antipasibotasunaren definizioari ondo egokitzen zaizkion alternantziak erakusten dituzten aditzak. Bere 2003ko lanean, de Rijk-ek hamalau aurkitu zituen guztira: gogoratu, oroitu, ahaztu, ahantzi, trufatu, burlatu, baliatu, erditu, errukitu, hautatu, gozatu, mintzatu, nagusitu eta eskarniatu. Egitura antipasiboetan hiztunak aditz iragankor bat iragangaitz gisa baliatzen du sintaxian, barne-argumentua PoS kategoriara 'degradatuta'; hizkuntza ergatiboetan, moldaketak kanpo-argumentuaren ohiko ERG kasua ABS bihurtu eta izan aditz laguntzailea agerrarazten du aditz jokatuan:

13. Eskerrak eman nahi dizkiot Beatriz Fernández lankideari garrantzizko puntu hau gogorarazteagatik. 
(8) Gogora ezazu umeak gauero tapatzea / Gogora zaitez umeak gauero tapatzeaz

(9) Ederki baliatu du emandako aukera / Ederki baliatu zen emandako aukera

Ikertzaileek (Ortiz de Urbina 1989, de Rijk 2003) hamalau alternantziak lexikotzat jotzen dituzte, egiturak ez duelako inongo produktibotasunik hizkuntzan. ${ }^{13}$

Hemen hamalau aditzak aztertzea proposatzen dut, emaitzek NOR-NORK eta NOR-ZERTAZ egituren erabilera-maiztasunak eta eremuak zehazteko aukera emango digutelako. Gainera, datuok aurreko atalekoekin alderatzen baditugu, hizkeren sistema ergatiboen konsistentzia ere analizatu ahal izango dugu, esan nahi baita ikusi ahal izango dugula ea bat datozen atal bietan izan/*edun edo ABS/ERG txandaketen azpian dauden irizpide semantikoak.

\section{Antipasiboak}

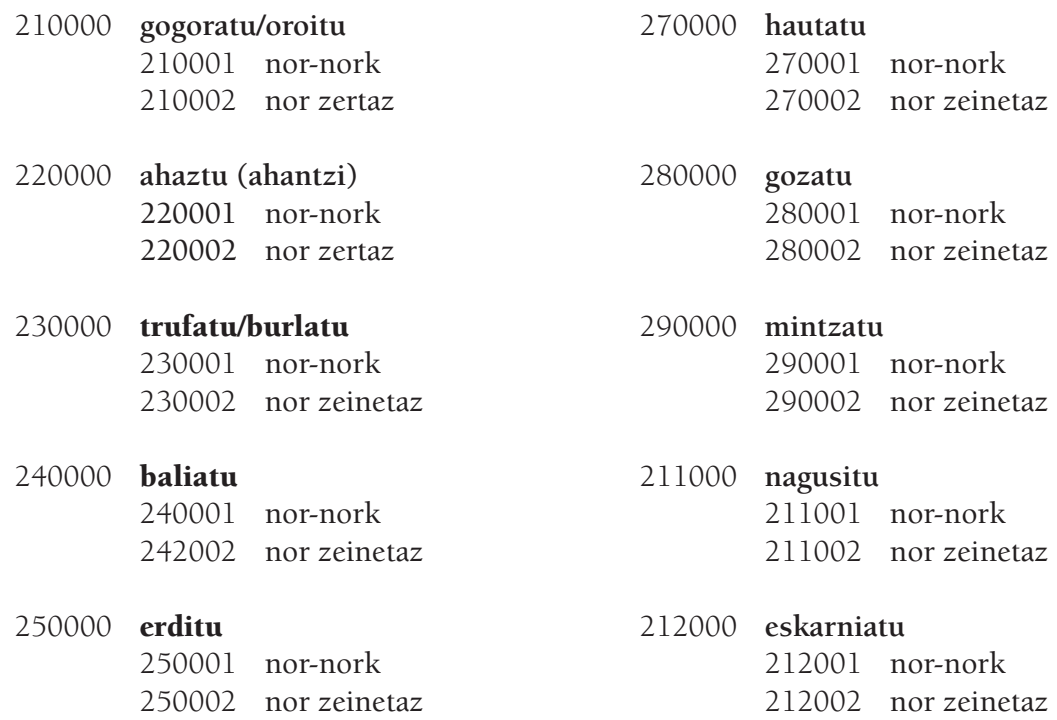

260000 errukitu

260001 nor-nork

260002 nor zeinetaz

14. Zenbait lanek Gramatika Sortzailearen ikuspuntutik aztertu dituzte egitura hauek. Honakoak dira: Hualde (1988), Ortiz de Urbina (1989), Albizu (2001) eta Rezac (2007abc). 


\subsection{Bihurkari-elkarkari ez-kanonikoak}

Ezaguna da euskaldunok ez-kanonikoa den bigarren estrategia bat darabilgula bihurkaritasuna eta elkarkaritasuna adierazteko. ${ }^{14}$ Estrategia hori dela medio, predikatu iragankor baten ergatibotasuna erabat galtzen da, hau da, ERG gabe subjektuak ABS kasua hartzen du eta izan aditz laguntzaileak *edun ordezkatzen du:

(10) Aitorrek oso ondo zaintzen du bere burua / Oso ondo zaintzen da Aitor

(11) Bi taldeek ez dute elkar errespetatzen / (*)Bi taldeak ez dira batere errespetatzen

Itxura batean estrategia askoz hedatuago dago Hegoaldean Iparraldean baino, eta batez ere mendebaldeko hizkeretan. Etxepare (2003b) lanean dugu fenomenoaren deskribapen osoena. Bi faktore nagusi aipatzen ditu bihurkari-elkarkari ez-kanonikoen erabilera mugatzen dituztenak. Lehena sintaktikoa da, garrantzia baitauka "desagertarazitako" anafora lexikoak egitura bihurkarielkarkari kanonikoan agertuko lukeen kasuak; izan ere, posible da ABS-z markatutako anafora bati dagokionean (12a), askoz onargaitzagoa DAT-ari dagokionean (12b), eta guztiz ezinezkoa zeharkasu bati dagokionean (12c):
(12) a. Jon goizean orraztu da
ABS
b. (*)Proposatu naiz aurten lan gutxiago egitea
DAT
c. Nire aita arduratzen da *(bere buruaz)
Po (Albizu 2001)

Bigarrena, berriz, semantikoa da, aditz inkoatiboek (erre, puztu, ito, nahastu...), egoera-aditzek (maite izan, ezagutu, miretsi, hobetsi...) eta irudikapen aktiboko aditzek (errepresentatu, irudikatu eta erakutsi) ERG egitura eskatzen dutelako, ustez:
(13) a. *Jon gasolinarekin erre da 'erre du bere burua'
(inkoatiboa)
b. *Ume hori gehiegi maite da
(egoera)
c. *Koroa batekin errepresentatzen naiz koadroetan
(irudikapen aktiboa)

Fenomenoa sintaktikoa da argi eta garbi, ez lexikoa; bestela ezin genuke azaldu ondorengo egitura iragankor peto-petoek erakusten duten kasua:

(14) a. (*)Etxe berria erosi naiz

b. (*)Proposatu naiz aurten lan gutxiago egitea

(Euskaltzaindia, 1987:56)

(Albizu, 2007)

Galdegai-zerrendan aurreko guztiak sartu ditut inkoatiboak izan ezik. Estrategia onar lezaketen 8-9 aditz agentiboz [311100 eta 312100] ordezkatu ditut. Oro har, ustez hizkeretan alternantziak eman litzaketen aditzak aukeratu ditut zerrendarako. Salbuespen dira horretan zeharkasuak [313000], zeren garrantzitsu iritzi diot murriztapen gramatikala datu-bilketaren bitartez baieztatzeari. 


\section{Bihurkari-elkarkari ez-kanokikoak}

\section{Bihurkariak}

311000 ABS

311100 Agentiboak ${ }^{15}$

311110 jantzi \{ERG bere burua / ABS

311120 garbitu \{ERG bere burua / ABS

311130 sendatu \{ERG bere burua / ABS

311140 zaindu \{ERG bere burua / ABS

311150 prestatu \{ERG bere burua / ABS

311160 aurkeztu \{ERG bere burua / ABS \}

311170 babestu \{ERG bere burua / ABS \}

311180 goraipatu \{ERG bere burua / ABS \}

\section{Egoera-aditzak}

311210 maite izan \{ERG bere burua / ABS \}

311220 ezagutu \{ERG bere burua / ABS \}

311230 gorrotatu \{ERG bere burua / ABS

\section{Irudikapen aditzak}

311310 errepresentatu \{ERG bere burua / ABS \}

311320 irudikatu \{ERG bere burua / ABS \}

312000 DAT

\section{Agentiboak $^{15}$}

312110 jantzi \{ERG bere buruari / ABS

312120 zikindu \{ERG bere buruari / ABS

312130 sendatu \{ERG bere buruari / ABS $\}$

312140 prestatu\{ERG bere buruari / ABS \}

312150 hautsi \{ERG bere buruari / ABS

312160 proposatu\{ERG bere buruari / ABS \}

312170 erosi \{ERG bere buruari / ABS $\}$

\section{Zehar-kasuak}

313100 -gan sinetsi

313200 -z fidatu

$313300-z$ arduratu

313400 -rekin kexu izan

Elkarkarietan zertxobait aldatzen dira egitura ABSa onartzen duten testuinguruak. Horrela, Etxeparek (a) bezalakoak ontzat ematen ditu eta (b) modukoak gaitzesten:

(15) a. Zenbat maite diren bi ahizpak!

b. *Gehiegi maite da neska hori

15. Multzo honetan sartu ditut jabetza besterezina adierazten duten besoa hautsi da edo aurpegia zikindu da erako egiturak, nahiz eta halakoetan ez dagoen argi oinarrian zer dugun, DAT-ABS jabetza-harremana (berari besoa/aurpegia) edo izen sintagmaren barnekoa (alegia, bere besoa/aurpegia). Bestalde, aditz hauekin agentibotasun-maila ere kontrolatu beharko da, Etxeparek (2003) aipatu bezala, egitura hauek ez baitute subjektuaren egiletasuna lagun —Mikel besoa (??nahita) hautsi da. 
Faktore hori neurtze aldera, zerrenda bertsua proposatu dut bihurkarietarako zein elkarkarietarako. Diferentzia bakarra da bigarren honetan hiruzpalau aditz aldatu —orraztu [321100] jantzi-ren [311100] eta eman [322170] erosi-ren [312190] ordez- edo gehitu ditugula - galdetu eta kasu egin [322180-322190]. Elkar zenbaitetan parentesien artean emanez, adierazi nahi izan dut ez dugula baztertu behar hiztunek izan aditz laguntzailea izenordain elkarkariarekin, hala elkarrekin nola bata bestearekin batera erabiltzea (16c):

(16) a. Lagun onek \{elkar/bata bestea\} babesten dute beti

b. $(*)$ Lagun onak beti babesten dira

c. $(*)$ Lagun onak \{elkar/bata bestea\} babesten dira beti

\section{Elkarkariak}

321000 ABS

321100 Agentiboak

321110 orraztu \{ERG elkar / ABS (elkar)\}

321120 garbitu \{ERG elkar / ABS (elkar)\}

321130 sendatu \{ERG elkar / ABS (elkar)\}

321140 zaindu \{ERG elkar / ABS (elkar)\}

321150 prestatu \{ERG elkar / ABS (elkar)\}

321160 aurkeztu \{ERG elkar / ABS (elkar)\}

321170 babestu \{ERG elkar / ABS (elkar)\}

321180 goraipatu \{ERG elkar / ABS (elkar)\}

321190 eman $\{$ ERG elkar / ABS (elkar) \}

321200 Egoera-aditzak

321210 maite izan \{ERG elkar / ABS (elkar)\}

321220 ezagutu \{ERG elkar / ABS (elkar)\}

321230 gorrotatu \{ERG bere burua / ABS (elkar)\}

321300 Irudikapen aditzak

321310 errepresentatu \{ERG elkar / ABS \}

321320 irudikatu \{ERG elkar / ABS\}

322000 DAT

322100 Agentiboak

322110 jantzi \{ERG elkarri / ABS (elkarri)\}

322120 zikindu \{ERG elkarri / ABS (elkarri)\}

322130 sendatu \{ERG elkarri / ABS (elkarri)\}

322140 prestatu \{ERG elkarri / ABS (elkarri)\}

322150 hautsi \{ERG elkarri / ABS (elkarri)\}

322160 proposatu \{ERG elkarri / ABS (elkarri)\}

322170 eman \{ERG elkarri / ABS (elkarri)\}

322180 galdetu \{ERG elkarri / ABS (elkarri)\}

322190 jaramon/kasu egin \{ERG elkarri / ABS (elkarri) \}

323000 Zehar-kasuak

323100 -gan sinetsi 


$$
\begin{array}{ll}
323200 & -z \text { fidatu } \\
323300 & -z \text { arduratu } \\
323400 & \text {-rekin kexu izan }
\end{array}
$$

\subsection{Predikatu konplexuak}

Behar, nahi, ezin eta ahal aditz modalek predikatu konplexuak osatzen dituzte mendeko predikatuarekin. Halakoetan aditz ez-akusatiboekin bakarrik antzeman daitekeen kasu-alternantzia gertatzen da subjektuaren kasua zeinek determinatzen duen: aditz modala nagusitzen bada, ergatiboz markatuta agertuko zaigu eta aditz laguntzailea *edun izango da; mendeko aditz ez-akusatiboa gailentzen bazaio, berriz, subjektua absolutibozkoa izango da eta aditz laguntzailea izan:

(17) a. \{Umeak/Umeek\} hondartzara joan behar/nahi \{dira/dute $\}$

b. \{Umeak/Umeek\} berandu etorri ahal \{dira/dute\}

c. Elurtza hauekin \{mendizaleak/mendizaleek\} ezin izan $\{$ dira/dute $\}$ inora atera

Jakina denez, mendeko NOR-NORI predikatuekin modalaren eragina neutralizatu egiten da eta, beraz, absolutibozko subjektua eta izan aditz laguntzailea ditugu printzipioz aukera bakarrak (18). ${ }^{16}$ Hala ere, nik neuk susmoa dut okertzat jotzen ditugun horiek gazteen edo gazteenen artean zabaltzen hasiak direla

(18) a. $\{$ Familia/*Familiak $\}$ hurbildu behar/nahi $\{$ zaio/*dio\}, baina ez diete uzten

b. Orain bai, $\{$ familia/*familiak\} hurbildu ahal $\{$ zaio/*dio\} gaixoari

c. $\{$ Peru $/ *$ Peruk $\}$ ezin izan $\{$ zaio/*dio\} Mireni bidean elkartu

Bariazio horri OEH IV-k (304. orr.) eta Goenagak (2006) nabarmendutako zenbait alderdi gaineratu behar zaizkio, zeren lan horietan esan bezala gutxienez beste hiru faktorek eragin diezaiokete ez-akusatibo + behar predikatuko subjektuaren ergatibotasunari —betiere *edun aditz laguntzaileari eusten zaiola: ${ }^{17}$ (i) subjektua perpausa izateak (19), (ii) aditza edo kopulatiboa edo existentziala izateak (20), eta (iii) subjektua aditzaren eskuinaldean agertzeak (21). Hiru adibideak Goenagaren lanetik atera ditut, lehena OEHren aipamen batekoa eta hurrengo biak berak aurkituak:

(19) "Eta oriek menderatzea...izan behar du...egitekorik andiena" (Gco II, 31)

(20) "Itsaso gaizto samarra egon behar du" (R. Illarramendi, Testimonio falsoa, 5)

(21) "Oraintxen laster izan behar du meza"

Horiek guztiak zerrendako [411000-412000] galdegaietan jaso ditut. Eta irudia osatze aldera, azkenengoz kontuan hartu beharko dugu aurreko ataleko egitura bihurkari-elkarkari ez-ka-

16. Euskaltzaindiak (2001) salbuespen bat, OEHn (IV:305) jasotako Zaitegiren lotu behar diogu aipatzen du.

17. Egia esanda, laugarren bat ere aipatzen du Goenagak (2006), zehazki, bide partikula modalarenaren balio berdintsua izatea, hau da, ondorengo adibidean antzeman daitekeena:
(i) Larunbata iluntzen hasia izan behar zuen (P. Ezkiaga 0008)
[Goenaga (2006:401)] 
nonikoak modalekin batutakoan gertatzen dena [413000]; izan ere, ez-akusatiboa + nahi + ${ }^{*} e d u n$ darabilgun zenbait hiztunok errazago onartzen ditugu — guztiz onak izan gabe- (??)dantzaldirako prestatu nahi da erako esaldiak *etxera etorri nahi da tankerakoak baino (Albizu 2007).

\section{Predikatu konplexuak}

410000 Behar / Nahi / Ahal / Ezin

411000 nor aditzak

411100 atera behar

411110 SUBJ atera behar

411200 mintzatu behar

411120 atera behar SUBJ

411210 SUBJ mintzatu behar

411220 mintzatu behar SUBJ

411300 izan behar

411310 SUBJ izan behar

411311 SUBJDetS izan behar

411320 izan behar SUBJ

411312 SUBJ-TZE PERPAUSA izan behar

411321 izan behar SUBJDetS

411322 izan behar SUBJ-TZE PERPAUSA

412000 nor-nori aditzak

412100 atera behar (posesibo-igoera)

412110 SUBJ atera behar

412120 atera behar SUBJ

412200 iruditu (begitandu, agertu) behar

412310 SUBJ iruditu behar

412311 SUBJDetS iruditu behar

412312 SUBJ-TZE PERPAUSA iruditu behar

412320 iruditu behar SUBJ

412321 iruditu behar SUBJDetS

412322 iruditu behar SUBJ-TZE PERPAUSA

412300 mintzatu behar

412310 SUBJ mintzatu behar

412320 mintzatu behar SUBJ

413000 bihurkari eta elkarkari ez-kanonikoak

413100 jantzi

413200 alkandora jantzi

413300 ezagutu

413400 kasu egin

Aditz modalek ez ezik, ari progresiboak ere bariaziorako bidea ematen digu. Hala gertatzen da, batetik, aditz metereologikoekin (22) eta, bestetik, mendeko aditz iragankorrekin (23) ari-ren izaera diferentziak —aditza edo aspektu-marka (Laka 2006)_ direla medio:

(22) Euria ari $\{d u / d a\}$

(23) Euskara ikasten ari $\{d u / d a\}$ 
Aditz ez-akusatiboei begiratuta, ez daukagu printzipioz inongo aldakortasunik (23)-ko bi sistemen artean, biek kasu-markatze absolutiboa ematen digutelako. Hala ere, badago litekeen hirugarren sistema bat ere, ikertzaileok, aukera gisa behintzat, gogoan hartu behar genukeena. Alegiazko sistema horretan, aditz modalen ezin du joan/joan \{behar/ahal/nahi\} du ereduei jarraituta euskaldun (oso gazte?) batek etxean sartzen ari du erakoak sor litzake [421000]. Ba al dago halakorik? Eta modalen parekoak izanez gero, ezinbestean aztertu behar genituzke bai nor-nori predikatuak [422000] bai bihurkari-elkarkari ez-kanonikoak [424000]:

420000 Ari

421000 nor

421100 zertan ari

421200 euria ari

421300 sartzen ari

422000 nor-nori

422100 euria ari

422200 ateratzen ari (jabe-igoera)

422300 iruditzen/gustatzen ari

423000 nor-(nori-)nork (ekartzen ari)

423100 nor-nork

423200 nor-nori-nork

\section{0 bihurkari eta elkarkari ez-kanonikoak}

424100 orrazten ari

424200 alkandora janzten ari

424300 ezagutu

424400 kasu egin

\subsection{Aditz trinkoen eta perifrastikoen arteko asimetriak}

Aditzek sarri erakusten dituzte kasu-alternantziak euskaraz. Batzuetan, aditz berak erabilera ERG-dunak zein ERG-gabeak dauzka, haien arteko diferentzia semantikoak direla medio (24). Bes te zenbaitetan, hala gertatzen da ageriko diferentzia semantikorik gabe ere (25). Eta, bukatzeko, beste askotan egitura sintaktikoak berak, alegia, perpaus motak berak inposatzen dio txandaketa —boz ertainak (26a), inpertsonalak (26b) edota bihurkari-elkarkari ez-kanonikoak (26c).

(24) a. Ez al dizkiozu eskerrak eman oraindik?

b. Ama negar egiteari eman zitzaion

(25) a. Zertan jardun \{dute/dira\} egun osoan?

b. Bi malko lodi isuri \{zituen/zitzaizkion\}

(26) a. Oso erraz edaten da Nafarroako ardo beltz hori!

b. Ez da ezer saldu goiz osoan

c. Nor ez da oraindik orraztu?

Forma perifrastikoak ederki egokitzen dira aditzen unean uneko kasu-premietara, horretan *edun/izan aditz laguntzaileen txandakatzeaz baliatzen direlako. Forma trinkoek, ordea, oso kasu- 
molde zurruna agertzen dute, ergatiboa izatea edo ez izatea berezkoa, morfologian bertan finkatuta edukiko balute bezala. Horren erakusgarri dira kasu-moldearen aldaketa eskatzen duten egituretan, hau da, inpertsonaletan eta perpaus bihurkari-elkarkari ez-kanonikoetan adizki trinkoek agertzen duten debeku zorrotza (Albizu 2003). Ikusi, bestela, (27)-ko eta (28)-ko adibideak:18

(27) a. Orain hobeto ezagutzen dute elkar vs.

b. Orain hobeto dazagute elkar vs.

(28) a. Donostiara daramate arraina une honetan

b. Donostiara darama arraina une honetan
Orain hobeto ezagutzen dira

Orain hobeto dazagute (*elkarkaria)

(inpertsonala)

(*inpertsonala)

Hori horrela, trinkoen eta perifrastikoen arteko asimetria garrantzitsua da, ez beharbada fenomenoaren banaketa dialektala mugatzeko —ziurrenik eremu osokoa izango da—, baizik eta sistemaren ergatibotasunaren izaera bera finkatzeko. Esan nahi baita kontraste horrekin euskararen ergatibotasuna, semantikoa edo sintaktikoa ez ezik, fenomeno morfologikoa ere badela. Eta azken hau erakuste aldera, halako asimetriak bilatu nahi ditut ikusi, ezagutu eta eman aditzen erabilera bihurkariak baliatuta [510000-530000].

\section{Adizki perifrastikoak eta trinkoak}

\begin{tabular}{|c|c|c|c|c|}
\hline \multirow[t]{10}{*}{510000} & \multicolumn{4}{|c|}{ Ikusi (bihurkaria) } \\
\hline & \multirow[t]{5}{*}{511000} & \multicolumn{3}{|c|}{ Perifrastikoa } \\
\hline & & 512100 & Bere burua & norberaren burua ondo ikusi \\
\hline & & 512200 & Ez-kanonikoa & ondo ikusi + izan \\
\hline & & & 512210 Ikusi da & \\
\hline & & & 512220 Ikusten ari da & (kontrolerako) \\
\hline & 512000 & Trinkoa & & \\
\hline & & 512100 & Bere burua & norberaren burua ondo ikusi \\
\hline & & 512200 & Ez-kanonikoa & ABS ondo ikusi \\
\hline & & 512300 & Bihurkaria ez den perpausa & (kontrolerako) \\
\hline
\end{tabular}

520000 Ezagutu (elkarkaria)

521000 Perifrastikoa

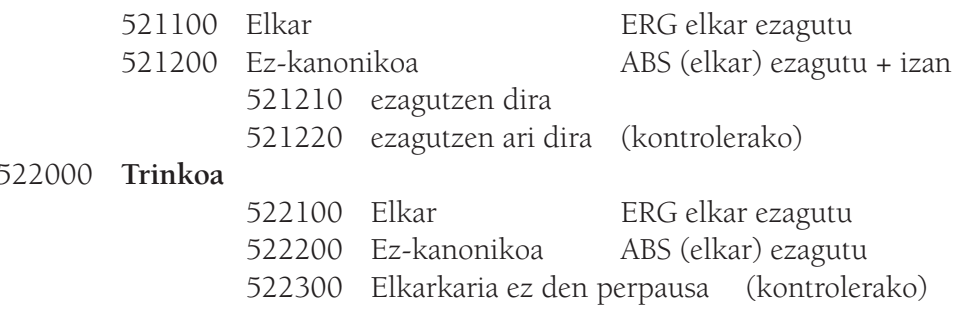

18. Balio aspektualak ez dauka zerikusirik kontrastean, ondorengo ari-dun adibideek erakusten duten bezala —beste ikuspuntu baterako, ikusi Ortiz de Urbina (1993 2003b):
(i) Hobeto ezagutzen ari dira
(elkarkaria)
(ii) ?Donostiara eramaten ari da arraina une honetan
(inpertsonala) 


\section{Eman (bihurkaria)}

531000 Perifrastikoa

$\begin{array}{lll}531100 & \text { Bere burua } & \text { ERG norberaren burua eman } \\ 531200 & \text { Ez-kanonikoa } & \text { ABS eman + izan }\end{array}$

Ildo beretik, aztertu beharrekoak dira erabilera ERG-dunak zein ERG-gabeak edukita (alegia, (24)-koen eta (25)-ekoen tankerakoak), joko biak, hala perifrastikoa nola trinkoa, erakusten dituzten aditzak. Bakanak dira: jarraiki, jardun, erion, atxiki, irudi, eman [540000-590000] eta agian ihes egindako besteren bat. Zeren oso litekeena da zenbait hizkeratan — gutxitan ziurrenik- aditzaren formak bereiztea haien kasu-portaera. Esate baterako, ba al dago NOR-NORK den dihardu-rekin batera NOR kasu-markatzea duen jardun da bakarrik erabiltzen duenik? Edo darraio-rekin (NORNORI) batera jarrai (ki)tzen diot (NOR-NORI-NORK) erabiltzen duenik? Eta hori zinez interesgarria litzateke berriro ere ergatibotasunak motibazio morfologikoa edukiko lukeelako.

540000 Jarraitu (jarraiki)

541000 Perifrastikoa: $\{$ ABS _ zaio / ERG _ dio\}

542000 Trinkoa: $\{$ ABS / ERG $\}$

543000 Ari

550000 Jardun (ihardun, ikarduki)

551000 Jardun 'aritu'

551100 Perifrastikoa: $\left\{\mathrm{ABS}_{-}\right.$da / ERG _ du

551200 Trinkoa: $\{$ ABS / ERG $\}$

552000 Jardun 'hitz egin'

552100 Perifrastikoa: $\left\{\mathrm{ABS}_{-}\right.$da / ERG _ du

552200 Trinkoa: $\{$ ABS / ERG $\}$

560000 Erion (jario/jariatu)

561000 nor-nori

561100 Perifrastikoa

tximiniari kea

561200 Trinkoa

562000 nor-nork

562100 Perifrastikoa

tximiniak kea

570000 Atxiki

562200 Trinkoa

571000 nor-nori

571100 Perifrastikoa

zura azalari atxiki

571200 Trinkoa

572000 nor-nork ('eutsi, heldu')

zaldia atxiki

572100 Perifrastikoa

572200 Trinkoa

580000 Iruditu

581000 nor-nork

581100 Perifrastikoa

581200 Trinkoa

582000 nor-nori-nork

zuzen(a) iruditu

582100 Perifrastikoa

582200 Trinkoa

zuzen(a) iruditu 


$\begin{array}{lll}583000 & \text { nor-nori } & \\ & 583100 & \text { Perifrastikoa } \\ & 583200 & \text { Trinkoa }\end{array}$

\section{Eman}

$\begin{array}{ll}591000 & \text { nor-nork } \\ & 591100 \quad \text { Perifrastikoa } \\ & 591200 \quad \text { Trinkoa } \\ 592000 & \text { nor-nori-nork } \\ & 592100 \quad \text { Perifrastikoa } \\ & 592200 \quad \text { Trinkoa }\end{array}$

593000 nor-nori 'lotu, atxiki'

593100 Perifrastikoa

593200 Trinkoa zuzen(a) iruditu

$$
\text { eman ...-ela }
$$

zerbait norbaiti eman

eman zerbaiti/zerbaitera

Edonola ere, onartu behar dut, adizki trinkoen erabilera-urria dela eta, oso zaila izango dela atal honetan jomuga ditugun datuak jasotzea.

\subsection{Aditz ez-akusatiboekiko NOR-(NORI)-NORK komunztadura bitxia}

Ergatibotasunarekin lotu ohi den ${ }^{*}$ edun erroa ${ }^{19}$ daramaten NOR-NORK edo NOR-NORI-NORK aditz laguntzaileez lagunduta agertzen zaizkigu aditz ez-akusatiboak zenbait hizkeratan. Horren adibide dira Fernándezek (2004) Hondarribiakoan jaso dituen ondoko erabilerak:

\section{(29) a. Niri sagarrak gustatzen nauzki \\ b. Zuri marmitakoa gustatzen dizu}

Lehenengoan, izan/*edun txandakatzea Datiboaren lekualdatzea edo solecismo de la costa deritzon fenomenoarekin batera gertatzen da. ${ }^{20}$ Hau da, adizki jokatuak ohiko pertsona-atzizkiak gabe, aurrizkiak darabiltza DAT argumentuarekiko komunztadura markatzeko. ${ }^{21}$ Bigarrenean, berriz, adizki jokatuak DAT komunztadurari eusten dio, eta ABS argumentuari dagokionez, duda-mudakoa da komunztadura ABSkoa ala ERGkoa den. ${ }^{22,23}$

19. *Edun-en definizio morfologikoa sinplifikatzen ari naiz hemen. Zehaztasun gehiago nahi dituenak jo dezala Albizu (2002) eta Fernández (2004) lanetara.

20. Arregirenak (2001; Arregi eta Nevins 2008) eta batez ere Fernándezenak (2001, 2004; Fernández eta Ezeizabarrena 2001) eta Rezacenak (2007b, 2008 ale hau) ditugu gaiaren inguruko lan nagusiak. Gaian interesa duenak erreferentzia ugari aurkituko ditu azken bi ikertzaileen lanetan.

21. NOR-NORI aditzetako lekualdatzeak oso erabilera-esparru mugatua dauka, Gipuzkoako ipar goi-nafarreraren hizkereretako (Hondarribia, Irun eta Oiartzun, gutxienez) ezaugarria delako. Arruntagoa da NORNORI-NORK aditzetakoa, aurreko eremuan ez ezik Bizkaiko ekialdeko kostaldean (adibidez, Lekeition) eta Lapurdiko hegoaldean (esaterako, Saran) ere erabiltzen direlako.

22. Auzi honen inguruan hausnarketa interesgarria egin ondoren, Fernándezek (2004:102-103) ABS komunztaduraren alde argudiatu zuen. Argi-itzalak dauzkan arren, erakargarria da arrazoibidea.

23. NOR-NORI jokoa galtzeko joera erakusten duen fenomeno hau barreaiatu samar agertzen zaigu Bizkaian, Gipuzkoan eta agian Nafarroan barrena. Rezac-ek (2008, 18. oin-oharra) Ondarroa, Tolosa, Legazpi, Errenteria, Zarautz eta Lizarrako hiztun gazteengan aurkitu ditu.. 
Itxura batean, bai bateko bai besteko aditz laguntzailean gertatzen den ABS/ERG txandakatzea morfologikoa da, ez sintaktikoa, sagarrak eta marmitakoa subjektuek ABS kasuari eusten diotelako (Fernández 2001 2004, Fernández eta Ezeizabarrena 2001). Dena dela, Rezac-ek (2007b, 2008) halako testuinguruetan ERGkoak onartzen dituzten euskaldun gazteak aurkitu ditu Tolosan zein Errenterian.

ABS zein DAT argumentuen pertsonak zerikusi handia dauka fenomenoan. Tolosako (Rezac 2008) zein Ondarroako (Arregi 2004) hizkeretan, ABS argumentuak 1. edo 2. pertsonakoa izan behar du alternantzia gertatzeko (30); Hondarribikoan (Fernández 2004), NOR-NORK jokoa 1. pertsona singularreko DAT argumentuekin aurkitzen dugu bakarrik eta NOR-NORI-NORK jokoa gainontzekoekin (31):

(30) Zu niri es dostasu gustaten vs. Jon niri ez gasta gustaten

(31) Jon niri gustatzen nau vs. Jon guri gustatzen digu/ttiu

Gure galdera-sortarako, bi aditz aukeratuko ditugu —etorri [610000] eta gustatu (laketu) edo bururatu (otu) [620000] — morfologiak kontrakoa adierazi arren, oso egitura sintaktiko ezberdinak dituztelako biek (Artiagoitia 2000, Albizu eta Fernández 2006, Fernández 2007, Rezac 2008 ale hau). Izan ere, diferentzia horren isla dira Manterola ikertzaile hondarribitarrak bere hizkeran duen honako asimetria:

(32) Zu neri \{gustatzen/*hurbildu\} nazu

(Manterola, 2004:4)

Aditz bakoitzean pertsona-marken lau konbinazio sartu ditut faktore horren inportantzia mugatzeko. Guztietan, litezkeen hiru erantzunak jaso ditut: ABS_izan $\left(N-N_{i}\right)$ aukerak adierazten du hizkerak ez daukala lekualdatzerik; $A B S_{-}{ }^{*} e d u n\left(N-\left(N_{i}\right)-N_{k}\right)$ aukerak, alternantzia morfologikoa dela, eta $E R G_{-}{ }^{*}$ edun $\left(N-\left(N_{i}\right)-N_{k}\right)$ erantzunak, sintaktikoa dela.

\section{Nor-nori aditzak}

610000 Etorri

611000 hura-hari $\left\{\mathrm{ABS}_{\text {_ }}\right.$ zaio / ABS _ du-dio / ERG_du-dio\}

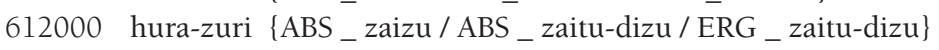

$613000 \mathrm{ni}-$ hari $\{\mathrm{ABS}$ _ natzaio / ABS _ dut-diot / ERG _ dut-diot $\}$

614000 ni - zuri $\left\{\mathrm{ABS}_{\text {_ }}\right.$ natzaizu / $\mathrm{ABS}_{\text {_ }}$ zaitut-dizut / ERG _ zaitut-dizut $\}$

620000 Gustatu (laketu) edo bururatu (otu)

621000 hura-hari $\left\{\mathrm{ABS}_{\text {_ }}\right.$ zaio / ABS _ du-dio / ERG _ du-dio $\}$

622000 hura-zuri $\left\{\mathrm{ABS}_{\text {_ }}\right.$ zaizu / $\mathrm{ABS}$ _ zaitu-dizu / ERG _ zaitu-dizu\}

623000 ni - hari $\{$ ABS _ natzaio / ABS _ dut-diot / ERG _ dut-diot $\}$

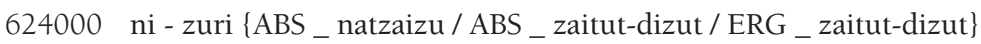

\subsection{Urruneko komunztadura}

Etxepare ikertzaileak (2003ab) luze eta sakon aztertu du euskarako urruneko komunztadura. Honetan, perpaus nagusiko aditz laguntzaileak berez perpaus berekoa ez den argumentu batekin komunztadura egin eta haren pertsona (33) zein numeroa (34) markatzen du:

(33) [Zu bisitatzen] segitzen ?du / zaitu 
(34) [Nobela beltzak irakurtzea] gustatzen zaio / zaizkio

Urruneko komunztadura gertatzea ala ez hainbat faktoreren menpe dago. Etxeparek predikatuen izaera, infinitiboekiko komunztadura, lokalitatea, menpeko subjektuaren izaera eta beste batzuk zehaztu ditu bere lanean. Gureari dagokionez, fenomenoak ez du printzipioz zertan eragin perpausaren ergatibotasunean, izan ere, NOR-(NORI)-NORK jokuko aditzek bakarrik onartzen baitute urruneko pertsona-komunztadura. Hala eta guztiz, Etxeparen (2003a) hizkeran badira NOR aditz gutxi batzuk —zehazki, hasi, aritu, ibili eta saiatu—urruneko komunztadura onartzeaz gainera ezusteko ABS/ERG txandakatzea dakartenak:24

(35) a. [Ni aspertzen] ari ?zinen

b. [e aspertzen] ari ninduzun

(Etxepare, 2003a:171)

(36) a. Saiatuko gara [zuri hori ematen]

b. Saiatuko dizugu [e e ematen]

(Etxepare, 2003a:173)

Gure galdera-sortak azken lau aditzen portaera hori aztertu eta identifikatu nahi du [722110722210-722310-732310]. Lau horiek kontrolerako diren beste datu-sorta batzuekin osatu ditugu: batetik, partizipiozko osagarriak dutenak [710000], NOR-(NORI)-NORK aspektu aditzak [721000] eta NOR-(NORI)-NORK berregituraketa aditzak [731000], aztergai ditugun hizkerek urruneko pertsona-komunztadura duten ziurtatzeko; bestetik, lau aditzen erabilera iragankor arruntak [722120-722220-722320-732320]:25

\section{Urruneko komunztadura}

710000 Partizipiozko osagarriak dutenak

711000 Behar

712000 Ahal

713000 Posible

720000 Aspektu aditzak

(kontrolerako)

721000 nor-(nori)-nork aditzak

721100 bukatu

721200 ekin

721300 utzi

722000 nor aditzak

722100 hasi

722110 urruneko komunztadura

722120 erabilera iragankor arrunta (kontrolerako)

722200 aritu

722210 urruneko komunztadura

722220 erabilera iragankor arrunta (kontrolerako)

722300 ibili

722310 urruneko komunztadura

24. Etxeparek berak (2003a:172) ohartarazten duenez, litekeena da salbuespenak izatea eta horien azpian aditzon NOR-NORK erabilerak edukitzea, esaterako, Tontoak bezala ibili gaituzte, Lana hasi du eta abar.

25. Ikusi 24. oin-oharra. 


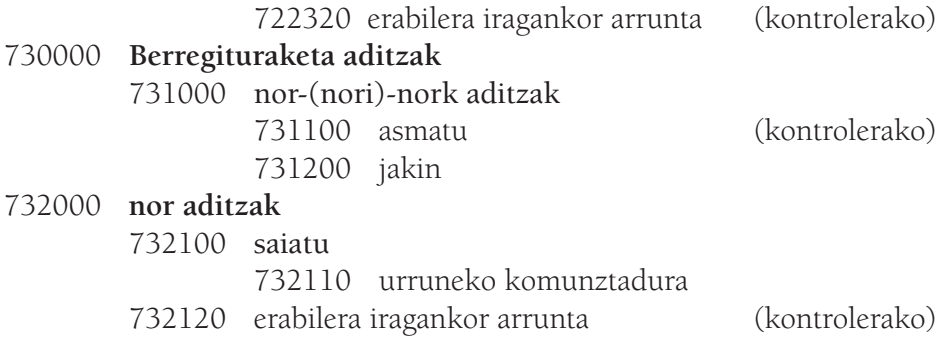

\subsection{Bi hitz datu-bilketako metodologiaz}

Behin bildu beharreko datuak zehaztutakoan, kontua da informazioa nola jaso. Espazio faltaren aitzakiaz, ezer gutxi esango dut hemen alderdi metodologikoari buruz. Badira Europan gurearen antzeko hainbat proiektu besteak beste, Syntactic Atlas of the Dutch Dialects (SAND), Syntactic Atlas of Northern Italia (ASIS), Scandinavian Dialect Syntax (ScanDiaSyn), Syntax of Hessian Dialects (SyHD) eta guk haien metodologiak eredutzat hartu eta gure premietara egokituko ditugu.

Horrela, bi fase bereiziko ditugu datu-bilketan: lehena, postaz egindako ikerketa pilotoa eta, bigarrena, aurrez aurreko elkarrizketa(k). Ikerketa-pilotorako esanguratsu izan daitezkeen 15 bat toki aukeratuko ditugu, eta bakoitzean hiru informatzaile. Ahal izanez gero, familia bereko hiru kide bilduko ditugu, hirurak belaunaldi ezberdinetakoak (20, 45 eta 70 urte ingurukoak). Diferentziak aldaera diastratikoak identifikatzen hasteko baliatuko ditugu; ezaugarri komunak, berriz, hizkeraezaugarrien sendotasuna baieztatzeko. Lehen fase honek datu-bilketan erabilitako metodoen edo galdetegien gabeziez ohartaraziko digu; gainera, ergatibotasunaren aldakortasunaren lehen irudia ere emango digu, zer aldatzen den eta non aldatzen den erakutsiko baitigu.

Ergatibotasunaren fenomenoa aztertzerakoan, hiru dira nire ustez bai lehen fasean bai bigarrenean erabili beharko ditugun metodoak:

i. itzulpen galderak (batutik hizkerara)

ii. osatzeko galderak (hutsuneak betetzekoak)

iii. iritziak emateko galderak (batez ere, aukera anitzetan onargarritasun mailak bereiztekoak)

Jakitun gaude hiru metodoek mugak dituztela (ikus, adibidez, Gerritsen 1993, Cornips \& Jongenburger 2001 eta Cornips \& Poletto 2005) eta, beraz, gaizki prestatu edo aplikatuz gero, ikerketa-lana zapuzteko edo, oraindik okerrago, ondorio makurretara iristeko arriskua dakartela. Arazo metodologikoei aurre egitea izango da aurrerantzean erronka nagusia.

\section{Laburbilduz}

Sinetsita nago ergatibotasuna dialektologikoki modu sistematikoan aztertzeak interes deskriptibo, dialektologiko zein teoriko handia daukala. Lehen urratsak egite aldera, ikerketaegitasmo hau prestatu eta plazaratu nahi izan dut: arlo metodologikoan heldugabe badago ere, proiektua aski garatuta dago eta oso zehatza da azterkizun diren aldagaiei dagokienez. Basdisyn-eko taldekideok egitasmo hau eta molde bertsuko beste zenbait proiektu prestatzen dihardugu orain, ahalegin horien fruituak, epe laburrean ez bada, epe ertainean jasoko ditugulako esperantzarekin. Nire uste apalean, helburuak betez gero lorpenak ez dira makalak izango. Alderdi deskriptiboan, ergatibotasunak hizkeraz hizkera erakusten duen sendotasuna neurtu ahal izango dugu. Gainera, sendotasuna ez ezik, ergatibosatunari eragiten dioten faktoreak ere, dela semantikoak, dela 
sintaktikoak edo morfologikoak, hizkeraz hizkera mugatu ahal izango ditugu eta, hari horretatik tiratuta, izenburuko galderari erantzun ahal izango diogu: kasu-sistema ergatibo bakarra ala gehiago ditugu euskal hizkeretan?

Dialektologiaren esparruari dagokionez, eta beharbada atrebentzia handiegia da nik hala esatea, iruditzen zait proiektuak, beste bide bat erakutsiz, zertxobait iraultzen duela dialektologiaren ikuspuntu tradizionala, zeren fenomeno sintaktiko partikularretatik harago eginez, makrofenomeno bat, ergatibotasuna hartzen dugu aztergai eta aldagai. Aurrekoaz gainera, esperantza dut ikerlan honek gure tradizio dialektologikoan batutako datuak osatuko dituela; izan ere, dialektologia-lanetatik kanpo gelditu ohi dira hemen jaso ditugun aldagaietako batzuk, esaterako, urruneko komunztadura. Onenean, datuek hizkeren ezkutuko ezaugarri bereizleak antzemango dituzte eta baliagarriak izango dira euskararen azterketa diatopikoan zein diastratikoan.

\section{Aipamenak}

Alberdi, Xabier. 2003a. "The transitivity of borrowed verbs in Basque: An outline". B. Oyharçabal (arg.), Inquiries into the lexicon-syntax relations in Basque. Leioa eta Donostia: EHU eta Gipuzkoako Foru Aldundia. 23-46.

—. 2003b. "Euskal aditz mailegatuen erregimena: hurbilketa". J.M. Makatzaga eta B. Oyharç bal (arg.), Euskal gramatikari eta ikerketari buruzko ikerketak XXI. mendearen atarian. Gramatika gaiak, Iker 14 (1). Bilbo: Euskaltzaindia. 37-60.

Albizu, Pablo. 2001. "Sobre la distribución sintáctica de las formas finitas del verbo vasco: condicionamiento léxico y sintáctico". ASJU 35:1, 65-106.

—. 2002. "Basque Verbal Morphology: Redefining cases". X. Artiagoitia, P. Goenaga eta J.A. Lakarra (arg.), Erramu Boneta: Festchrift for Rudolf P. G. de Rijk. Bilbo: EHU. 1-19.

—. 2004. "Dativos y ergatividad en vasco: condiciones sintácticas para un desencuentro". M. Villayandre (arg.), Actas del V Congreso General de Lingüística. Madrid: Arco/Libros. 211-222.

—. 2007. "Euskararen ergatibotasuna: ohar batzuk dakigunaz eta ez dakigunaz", Koldo Mitxelena Katedraren II. Biltzarra, Gasteiz 2007/10/08-11..

—. eta Beatriz, Fernández. 2002. "Datives' intervention effect on Ergativity in Basque". XII Coloquio de Gramática Generativa-n irakurritako txostena, Universidad Nova de Lisboa, Lisboa. (2002ko apirilaren 15-17a)

—. eta Beatriz, Fernández. 2006. "Licit and illicit ERG-DAT pairings". B. Fernández \& I. Laka (arg), Andolin gogoan. Essays in honour of Professor Eguzkitza. Leioa: EHU. 69-96.

Aldai, Gontzal. 2006. "Is Basque morphologically ergative? (I) "The semantic (i.e. split-intransitive) case-marking system of Western Basque". B. Fernández \& I. Laka (arg), Andolin gogoan. Essays in honour of Professor Eguzkitza. Leioa: EHU. 117-138.

Arregi, Karlos. 2004. "The Have/Be Alternation in Basque". MITko eskuizkribua, Cambridge Mass.

—. eta Andrew Nevins. 2008. "A Principled Order to Postsyntactic Operations". Univ. of Illinois at Urbana-Campaign eta Harvard University.

Artiagoitia, Xabier. 2000. Hatsarreak eta Parametroak Lantzen. Vitoria-Gasteiz: Arabako Foru Aldundia eta UPV/EHU.

—. 2001a. "Irudiak eta emaileak". ASJU 35:1, 29-64.

—. 2001b. "Seemingly ergative and ergatively seeming". J. Herschensohn, E. Mallén \& K. Zagona (arg.), Features and Interfaces in Romance. Essays in honor of Heles Contreras. Amsterdam/Phila- 
delphia: John Benjamins. 1-22.

Aurrekoetxea, Gotzon. 1996. "Hizkerak banatzeko ezaugarriez", ASJU 30, 127-143.

—. eta Bidegain, Xarles. 1993. "Euskal Herriko hizkuntz atlasa. Galdesorta-Cuestionario-Questionnaire", Euskera XXXVIII-2, 529-647.

Cornips, Leonie eta Willy Jongenburger. 2001. "Elicitation techniques in a Dutch syntactic dialect atlas project". H. Broekhuis \& T. van der Wouden (arg.), Linguistics in The Netherlands 18. Amsterdam/Philadelphia: John Benjamins. 57-69.

—. eta Cecilia Poletto. 2005. "On standardising syntactic elicitation techniques (part I)". Lingua $115,939-957$.

Etxepare, Ricardo. 2003a. "Menpeko infinitiboak eta urruneko komunztadura". Lapurdum 8, 167206.

—. 2003b. "Valency and argument structure in the Basque verb". J.I. Hualde eta J. Ortiz de Urbina (arg), A Grammar of Basque. Mouton de Gruyter: Berlin. 363-426.

Euskaltzaindia. 1995. "Ekartzea merezi du (31)", Euskaltzaindiaren Arauak, Bilbo: Euskaltzaindia. [http://www.euskaltzaindia.net/arauak/ dok/ProNor0031.htm]

—. 1987. Euskal Gramatika: Lehen Urratsak II. Bilbo: [http://www.euskaltzaindia.net/iker_jagon/ iker/gramatika]

—. 2001. "Behar/Nahi izan aditzaren jokabidea aditz iragangaitzekin (113-114)", Euskaltzaindiaren Arauak, Bilbo, Euskaltzaindia. [http://www.euskaltzaindia.net/arauak/ dok/ProNor0113.htm]

Fernández, Beatriz. 1997. Egiturazko kasuaren erkaketa euskaraz. Bilbo: UPV/EHU.

—. 2001. "Absolutibo komunztaduradun ergatiboak, absolutibo komunztaduradun datiboak: Ergatiboaren Lekualdatzetik Datiboaren Lekualdatzera”. B. Fernández \& P. Albizu (arg.), Kasu eta Komunztaduraren gainean. On Case and Agreement, Bilbo: UPV/EHU. 147-165. [internet-en eskuragarri: http://www.ehu.es/servicios/se_az/pags/frp03/c40filol.pdf]

—. 2004. "Gustatzen nau gustatzen dizu: aditz laguntzaile eta komunztadura bitxiak perpaus ezakusatiboetan”. P. Albizu \& B. Fernández (arg.), Euskal Gramatika XXI. mendearen atarian: arazo zaharrak, azterbide berriak, Gasteiz: Arabako Foru Aldundia. 87-112.

—. 2007. High and low datives in Basque bivalent constructions. Rutgers Universityko eskuizkribua. Rutgers, Connecticut.

- eta Mari Jose Ezeizabarrena. 2001. "Itsasaldeko solezismoa, Datiboaren Lekualdatzearen argipean". J.M. Makazaga eta B. Oyharçabal (arg.), Euskal Gramatikari eta literaturari buruzko ikerketak XXI. Mendearen atarian. Gramatika gaiak, Iker 14-1. Bilbo: Euskaltzaindia, 255-278.

Gerritsen, Marinel. 1993. "The Methodology of the Syntactic Atlas of Dutch (AND)". W. Viereck (arg.), Proceedings of the international congress of dialectologists: Historical Dialectology and Linguistic Change. Stuttgart: Franz Steiner Verslag. 343-367.

Goenaga, Patxi. 2006. "BEHAR-en lekua euskal hiztegian eta gramatikan". B. Fernández \& I. Laka (arg), Andolin gogoan. Essays in honour of Professor Eguzkitza. Leioa: EHU. 397-416.

Heath, Jeffrey. 1972. "Genitivization in Complement Clauses", ASJU 6:46-66.

Holmer, Arthur. 1999. "An active analysis of Basque ergativity”, Fontes Linguae Vasconum 31, 189225.

Lafitte, Pierre. 1944 [1962]. Grammaire basque (Navarro-Labourdin littéraire). Donostia: Elkar.

Laka, Itziar. 1993. "Unergatives that Assign Ergative Case, Unaccusatives that Assign Accusative". 
J.D. Bobaljik \& C. Phillips (arg.), Papers on Case and Agreement I, MITWPL 18. Cambridge, Mass.: MITWPL. 149-172.

—. 1995. "Thetablind case: Burzio's generalization and its image in the mirror". E. Reuland (arg.), Arguments and Case. Explaining Burzio's generalization. Amsterdam/Philadephia: John Benjamins. 103-129.

—. 2006a. "Deriving split-ergativity in the progressive". A. Johns et al. (arg.), Ergativity. Dordrecht: Springer. 173-195.

—. 2006b. "On the nature of case in Basque: structural or inherent?". H. Broekhuis et al. (arg.), Organizing grammar. Berlin: Mouton de Gruyter. 374-382.

Levin, Beth. 1983. On the Nature of Ergativity. Doctorego tesia, MIT, Cambridge, Massachusetts.

Manterola, Julen. 2004. "Datiboaren Lekualdatzeaz". EHUko eskuizkribua, Gasteiz.

Mitxelena, Luis \& Ibon Sarasola. 1989. Orotariko Euskal Hiztegia (II-IV). Bilbo, Euskaltzaindia.

Ortiz de Urbina, Jon. 1987. "Kasu ezarketa eta ez-ergatibitatea euskaraz". P. Salaburu (arg.), Sintaxi arazoak. Donostia: EHU. 35-48.

—. 1989. Parameters in the Grammar of Basque. Dordrecht: Foris.

—. 1991. "Deskripapenetatik azalpenetara euskal gramatikan". A. Arejita (arg.), Euskal Sintaxiaz. Bilbo: Labayru. 11-27.

—. 2003a. "Semiauxiliary verbs". J.I. Hualde \& J. Ortiz de Urbina (arg.), A Grammar of Basque. Berlin: Mouton de Gruyter.

—. 2003b. "Impersonal clauses". J.I. Hualde y J. Ortiz de Urbina (arg.), A Grammar of Basque Berlin: Mouton de Gruyter.

Oyharçabal, Beñat. 1992. "Structural Case and Inherent Case Marking: Ergaccusativity in Basque". J.A. Lakarra eta J. Ortiz de Urbina (arg.), Syntactic Theory and Basque Syntax. Donostia: Gipuzkoako Foru Aldundia. 309-342.

Rezac, Milan. 2007a. "(Structural) Ergative in Basque", MITko Workshop on Ergativity-n (2007-10) emandako hitzaldiko adibidetegia. Lehen atala.

—. 2007b. "Absolutive displacement in Basque", MITko Workshop on Ergativity-n (2007-10) emandako hitzaldiko adibidetegia. Bigarren atala.

—. 2007c. "Last-Resort Dependent Case", MITko Workshop on Ergativity-n (2007-10) emandako hitzaldiko adibidetegia. Hirugarren atala.

—. 2008. "The syntax of eccentric agreement: The Person Case Constraint and Absolutive Displacement in Basque". Natural Language and Linguistic Theory 28-1, 61-106.

—. Ale honetan. "Person restrictions in Basque intransitives".

Rijk, Rudolph P.G. de. 2003. "Antipasiboak euskaran". J.Ma. Makazaga eta B. Oyharçabal (arg.), Euskal gramatikari buruzko eta literaturari buruzko ikerketak XXI. mendearen atarian. Iker-14 (I). Bilbo, Euskaltzaindia. 385-394.

Salaburu, Pello. 1987. "IS-aren mugimendua". P. Salaburu (arg.), Sintaxi Arazoak. Donostia-San Sebastián, UPV/EHU. 65-79.

Zabala, Igone. 2004. "Los predicados complejos en vasco". E. Pérez Gaztelu, I. Zabala eta Ll. Gràcia (arg.), Las fronteras de la composición en lenguas románicas y en vasco. Donostia, Deustuko Unibertsitatea. 445-534. 
